\title{
Produção de mudas de meloeiro amarelo, sob cultivo protegido, em diferentes substratos
}

\author{
Tânia Regina Pelizza ${ }^{1}$ Fabiane Nunes Silveira ${ }^{2}$,Janaína Muniz', Anelise Hoffmann Bruscatto Echer ${ }^{4}$, \\ Tânia Beatriz Gamboa Araújo Morselli ${ }^{5}$
}

\section{RESUMO}

Mudas mal formadas e debilitadas comprometem o desenvolvimento das culturas. O objetivo deste trabalho foi avaliar a produção de mudas de meloeiro amarelo, sob cultivo protegido, em diferentes substratos. Este trabalho foi conduzido em telado, na Universidade Federal de Pelotas (RS), nos meses de novembro e dezembro. Testaram-se os seguintes substratos: T1 (vermicomposto bovino puro); T2 (substrato comercial Plantmax ${ }^{\circledR}$ ); T3 (substrato comercial Húmus Fértil ${ }^{\circledR}$ ); T4 (vermicomposto bovino 75\% + casca de arroz carbonizada 25\%) e T5 (solo $75 \%$ + vermicomposto bovino $25 \%$ ). Foram avaliados o índice de velocidade e a percentagem de emergência do $6^{\circ}$ ao $9^{\circ}$ dia; a altura, o comprimento da raiz principal, a massa seca das raízes e da parte aérea das mudas de meloeiro, aos 27 dias. Os substratos que proporcionaram maior índice de velocidade de emergência das mudas de meloeiro amarelo foram Húmus Fértil ${ }^{\circledR}$, vermicomposto bovino puro e vermicomposto bovino $75 \%$ mais casca de arroz carbonizada 25\%. Maior altura da muda é obtida com o substrato Húmus Fértil ${ }^{\circledR}$. O comprimento da raiz principal foi maior com o uso de vermicomposto bovino puro, Húmus Fértil ${ }^{\circledR}$, vermicomposto bovino puro mais casca de arroz carbonizada $\left(\mathrm{VB}_{75}+\mathrm{CAC}_{25}\right)$, em comparação com solo $75 \%$ mais vermicomposto bovino $25 \%$. A massa seca de raiz foi maior quando utilizado Húmus Fértil ${ }^{\circledR}$, em comparação com solo $75 \%$ mais vermicomposto bovino $25 \%$. É possível utilizar substratos isolados ou em combinação para a produção de mudas de meloeiro amarelo sob cultivo protegido. Porém, deve-se evitar o uso de solo $75 \%$ em combinação com vermicomposto bovino $25 \%$.

Palavras-chave: Cucumis melo L., casca de arroz carbonizada, propagação, telado, vermicomposto.

\section{ABSTRACT}

\section{Production of yellow melon seedlings in different substrates under protected cultivation}

Weak and malformed seedlings compromise the development of the crop. The objective of this study was to evaluate the production of yellow melon seedlings in different substrates under protected cultivation. The experiment was conducted in a greenhouse during November and December, at the Federal University of Pelotas (RS). The following substrates were tested: T1: bovine manure vermicompost; T2: Plantmax ${ }^{\circledR}$ substrate; T3: Húmus Fértil ${ }^{\circledR}$ commercial substrate; T4: bovine vermicompost 75\%+ carbonized rice bark 25\%; and T5: soil 75\%+bovine vermicompost $25 \%$. The evaluated variables were: the rate of speed and percentage of emergence from days 6 th to $9^{\text {th }}$; height; main

Recebido para publicação em 17/05/2011 e aprovado em 26/02/2013.

${ }^{1}$ Engenheira Agrônoma. Departamento de Agronomia, Universidade do Estado de Santa Catarina, Avenida Luiz de Camões, 2090, Bairro Conta Dinheiro, 88520-000, Lages, Santa Catarina, Brasil. trp_mestagro@hotmail.com (autor correspondente) Bolsista PRODOC/CAPES.

${ }^{2}$ Engenheira Agrônoma. Departamento de Agronomia, Universidade do Estado de Santa Catarina, Avenida Luiz de Camões, 2090, Bairro Conta Dinheiro, 88520-000, Lages, Santa Catarina, Brasil. fabinhans29@yahoo.com.br

${ }^{3}$ Economista. Departamento de Agronomia, Universidade do Estado de Santa Catarina, UDESC/CAV, Avenida Luiz de Camões, 2090, Bairro Conta Dinheiro, 88520-000, Lages, Santa Catarina, Brasil. janainamuniz@gmail.com

${ }^{4}$ Engenheira Agrônoma. Cooperativa de Consumo, Trabalho e Produção Teia Ecológica, Reservatório Sinott - 9 Distrito de Pelotas, 96115-000, Pelotas, Rio Grande do Sul, Brasil. anebrusc@yahoo.com.br

${ }^{5}$ Engenheira Agrônoma, Doutora. Departamento de Solos, Faculdade de Agronomia Eliseu Maciel, Universidade Federal de Pelotas, Caixa Postal 354, 96001-970, Capão do Leão, Rio Grande do Sul, Brasil. morselli@ufpel.edu.br 
root length; and dry mass of roots and shoots of the watermelon seedlings at 27 days. The substrates that provided the highest speed rate of emergence of yellow melon were Húmus Fértil ${ }^{\circledR}$, bovine manure vermicompost and bovine vermicompost $75 \%+$ carbonized rice bark $25 \%$. Increased seedling height was obtained with the substrate Húmus Fértil ${ }^{\circledR}$. The main root length was higher with bovine manure vermicompost, Húmus Fértil ${ }^{\circledR}$, soil $75 \%+$ bovine vermicompost $25 \%\left(\mathrm{SO}_{75}+\mathrm{VB}_{25}\right)$ than with $75 \%$ ground beef $+25 \%$ vermicompost. The root dry weight was higher with Húmus Fértil ${ }^{\circledR}$ than soil $75 \%$ +bovine vermicompost $25 \%$. It is possible to use substrates alone or in combination for the production of yellow melon seedlings in greenhouses. However, the use of soil $75 \%$ in combination with bovine vermicompost $25 \%$ should be avoided.

Key words: Cucumis melo, carbonized rice bark, propagation, greenhouse, vermicompost.

\section{INTRODUÇÃO}

O melão, uma das frutas mais exportadas pelo Brasil, tem sua produção nacional concentrada nos estados do Rio Grande do Norte, Ceará, Bahia e Pernambuco. Merece destaque o Rio Grande do Norte, que detém cerca de 50\% da produção nacional. No entanto, embora as condições climáticas ideais encontrem-se na região Nordeste (pouca chuva e muito sol), é possível explorar a cultura do meloeiro em qualquer parte do país (SENAR, 2007).

A produção de mudas sob cultivo protegido apresenta inúmeras vantagens, em relação ao sistema tradicional, em sementeira a céu aberto, como maior precocidade, menor possibilidade de contaminação fitopatogênica, maior relação percentual entre sementes plantadas e mudas obtidas, melhor aproveitamento da área destinada à produção de mudas, maior facilidade na execução de tratos culturais, como desbaste, irrigação, adubação, tratamento fitossanitário, menor estresse por ocasião do transplantio e redução do ciclo da cultura no campo (Bezerra, 2003).

A cultura do meloeiro é estabelecida principalmente por meio de semeadura direta. No entanto, em sistemas de produção mais tecnificados e quando são utilizados híbridos de meloeiro, utiliza-se o cultivo por transplantio de mudas. Assim, a produção de mudas em cultivo protegido é realizada em recipientes apropriados, como, por exemplo, bandejas de isopor, sacos plásticos ou copinhos de jornal. Tal condição permite que, a campo, seja obtido um cultivo mais homogêneo, pelo obtenção de mudas de maior vigor, crescimento da parte aérea e das raízes (Dias \& Costa, 2010).

Para a produção de mudas em recipientes, é necessário um material suporte, o substrato. De acordo com Kämpf (2005), a densidade, a porosidade e a disponibilidade de ar e água são as características físicas mais importantes de um substrato. Dentre as características químicas, incluem-se o $\mathrm{pH}$, a capacidade de troca de cátions e a salinidade.

Vários substratos podem ser adquiridos no mercado, como o Plantmax ${ }^{\circledast}$ e o Húmus Fértil ${ }^{\circledR}$ ou, ainda, é possível serem elaborados na própria propriedade, como a casca de arroz carbonizada e o vermicomposto. As principais vantagens da casca de arroz carbonizada são o baixo custo e as qualidades físicas que confere, como umidade, porosidade e drenagem adequadas. Em vista da fácil drenagem da água, quando utilizada sob nebulização intermitente, resulta em menor peso das bandejas, o que facilita o manuseio no viveiro (Zietemann \& Roberto, 2007). O substrato comercial Plantmax ${ }^{\circledR}$ tem como vantagem a uniformidade da composição química e física (Hoffmann et al., 2001). O Húmus Fértil ${ }^{\circledR}$ é um substrato que apresenta alto percentual de umidade, $\mathrm{pH}$ alcalino e bons teores nutricionais. Já o solo, sob condições de nebulização intermitente, apresenta pouca drenagem e também exige desinfestação, pois é fonte de disseminação de doenças (Hoffmann et al., 2005).

Assim sendo, o objetivo deste trabalho foi avaliar a produção de mudas de meloeiro amarelo, sob cultivo protegido, em diferentes substratos.

\section{MATERIAL E MÉTODOS}

Este trabalho foi conduzido em telado com $30 \%$ de sombreamento, pertencente ao Departamento de Fitotecnia da Faculdade de Agronomia Eliseu Maciel, da Universidade Federal de Pelotas (UFPEL/FAEM), sendo este equipado com nebulização intermitente.

Os dados climatológicos dentro do telado, durante a condução do experimento, foram temperaturas de $22,5^{\circ} \mathrm{C}$, $20,1^{\circ} \mathrm{C}$ e $18,5^{\circ} \mathrm{C}$, máxima, média e mínima, respectivamente; umidades relativas de 69,5,96,8 e 58,0\%, média, máxima e mínima, respectivamente.

As sementes de meloeiro amarelo foram adquiridas em casa agropecuária e semeadas em bandejas de poliestireno expandido, com 72 células. A semeadura foi realizada em 13 de novembro de 2007, sendo colocadas três sementes por célula. No dia 22 de novembro, procedeu-se ao desbaste das mudas, deixando-se apenas uma muda por célula.

O delineamento experimental utilizado foi o inteiramente casualizado, com cinco tratamentos, com três repeti- 
ções, e cada unidade experimental foi composta por 16 mudas, totalizando 240 plântulas. Os diferentes tipos de substratos utilizados, que constituíram os tratamentos, foram: T1: vermicomposto bovino puro (VB puro); T2: substrato comercial Plantmax ${ }^{\circledR}$ (PLA); T3: substrato comercial Húmus Fértil ${ }^{\circledR}$ (HF); T4: vermicomposto bovino $75 \%$ casca de arroz carbonizada $25 \%\left(\mathrm{VB}_{75}+\mathrm{CAC}_{25}\right)$ e $\mathrm{T} 5$ : solo $75 \%$ mais vermicomposto bovino $25 \%\left(\mathrm{SO}_{75}+\mathrm{VB}_{25}\right)$.

A avaliação das mudas foi realizada 27 dias após a semeadura, quando foram avaliados a altura da muda e o comprimento da maior raiz, determinados com auxílio de régua graduada, em centímetros. A altura foi obtida, medindo-se a distância entre o colo e o ápice da muda. Também foram determinadas a massa seca da parte aérea e a da raiz da muda. Para esta determinação, as mudas de meloeiro foram seccionadas, separando-se a parte aérea e a raiz, sendo esta lavada com água, a fim de ser retirado o substrato aderido. Posteriormente, o material foi acondicionado em sacos de papel e colocado para secar em estufa, com circulação de ar forçado, a $65^{\circ} \mathrm{C}$, por três dias. Em seguida, foram pesados em balança analítica. Para o cálculo do índice de velocidade de emergência (IVE), registrou-se, diariamente, o número de sementes germinadas, do $6^{\circ}$ ao $9^{\circ}$ dia. Consideraram-se como emergidas, as mudas que apresentaram os cotilédones totalmente livres. A percentagem de emergência foi calculada de acordo com Labouriau \& Valadares (1976).

Os dados experimentais foram submetidos à análise de variância e as médias, quando significativas, foram comparadas entre si por meio do teste de Tukey, a 5\% de probabilidade, utilizando-se o Programa Winstat (Machado \& Conceição, 2003).

\section{RESULTADOS E DISCUSSÃO}

A análise estatística evidenciou diferenças entre os substratos avaliados para as variáveis IVE, altura da muda, comprimento da raiz principal e massa seca das raízes. As variáveis percentagem de emergência e massa seca da parte aérea de mudas de meloeiro amarelo não apresentaram diferenças significativas entre os substratos. Houve sobrevivência de $100 \%$ das mudas no experimento (Tabela 1).

O IVE foi maior no substrato Húmus Fértil ${ }^{\circledR}$, sendo que este se igualou ao dos substratos vermicomposto bovino puro e vermicomposto bovino $75 \%$ mais casca de arroz carbonizada $25 \%$. Essa condição indica que estes substratos possibilitam uma emergência antecipada, em comparação com os demais substratos testados, o que é vantajoso sob o ponto de vista técnico. É possível que estes substratos tenham possibilitado condições de umidade e temperatura favoráveis para a emergência das sementes, pois, segundo Carvalho \& Nakagawa (2000), a água exerce influência sobre o processo de germinação e sua absorção promove o aumento de volume da semente e, com isso, ocorre o rompimento do tegumento, o que, por consequência, facilita a emergência da radícula e do caulículo. Da mesma forma, na ausência de fatores limitantes, a germinação ocorre em uma ampla faixa de temperatura, cujos limites dependem da espécie e do material genético, bem como das condições ambientais durante o processo de produção, do manejo pré e pós colheita e da sanidade do material biológico (Marcos Filho, 2005). Lima et al., (2010), em avaliação de diferentes substratos na qualidade fisiológica de sementes de melão de caroá, observaram que o substrato comercial Plantmax ${ }^{\circledR}$ apresenta maior índice de velocidade de emergência, em comparação com a areia lavada e areia lavada mais húmus de minhoca (2:1). A rapidez na emergência das plântulas, de acordo com Martins et al. (1999), é uma característica altamente desejável, pois quanto mais tempo a plântula permanece nos estádios iniciais de desenvolvimento, mais tempo fica sujeita às condições adversas do ambiente. Da mesma forma, acredita-se que uma plântula que permaneça longo período em seu recipiente inicial, tendo ele um espaço limitado, tem mais rapidamente esgotados os nutrientes presentes no substrato.

A altura de plântula, aos 27 dias, foi maior no substrato comercial Húmus Fértil $^{\circledR}$, seguida da altura no substrato Plantmax $^{\circledR}$, sendo que este se igualou ao substrato à base de vermicomposto bovino puro e à composição de vermicomposto bovino puro mais casca de arroz carbonizada $\left(\mathrm{VB}_{75}+\mathrm{CAC}_{25}\right)$. Smiderle et al. (2001) observaram, durante a avaliação de mudas de alface, pepino e pimentão, que o substrato Plantmax ${ }^{\circledR}$ foi o que apresentou melhores resultados quanto à altura das mudas, obtido aos 21 dias após a semeadura. Silva et al. (2007) verificaram que o substrato composto por Plantmax ${ }^{\circledR}$ mais húmus de minhoca apresentou os melhores resultados para altura de plântula de melão amarelo, cultivado em bandejas de poliestireno expandido, em telado. Neste experimento, o substrato Húmus Fértil ${ }^{\circledR}$ sobressaiu-se, em relação ao Plantmax ${ }^{\circledR}$. Dentre todos os substratos avaliados, o que apresentou maior limitação para este atributo foi a composição de solo $75 \%$ mais vermicomposto bovino $25 \%$.

Quanto ao comprimento da raiz principal, valores maiores e iguais foram obtidos para os substratos vermicomposto bovino puro, Húmus Fértil ${ }^{\circledR}$, vermicomposto bovino puro mais casca de arroz carbonizada $\left(\mathrm{VB}_{75}+\mathrm{CAC}_{25}\right)$, sendo que Plantmax ${ }^{\circledR}$ igualou-se a estes e ao solo $75 \%$ mais vermicomposto bovino $25 \%\left(\mathrm{SO}_{75}+\mathrm{VB}_{25}\right)$, sendo esta a combinação de substrato que apresentou menor comprimento da raiz principal. Smiderle et al. (2001) observaram resultados distintos para o comprimento das raízes de alface, pepino e pimentão, quanto ao uso de diferentes substratos, quando, aos 21 e 40 dias após a semeadura, observaram-se resultados distintos para as culturas avaliadas. 
Tabela 1. Percentagem de emergência (EMG), índice de velocidade de emergência (IVE), altura (H), massa seca da parte aérea (MSPA), comprimento da raiz principal (CR) e massa seca das raízes (MSR) de mudas de meloeiro amarelo sob cultivo protegido em diferentes substratos. Pelotas -UFPel/FAEM

\begin{tabular}{lclcccc}
\hline Tratamentos & $\begin{array}{c}\text { EMG } \\
(\boldsymbol{\%})\end{array}$ & $\mathbf{I V E}$ & $\begin{array}{c}\text { H } \\
\mathbf{c m}\end{array}$ & $\begin{array}{c}\text { MSPA } \\
\text { g planta }\end{array}$ & $\begin{array}{c}\text { CR } \\
\mathbf{c m}\end{array}$ & $\begin{array}{c}\text { MSR } \\
\text { g planta }\end{array}$ \\
\hline VB puro & $100 \mathrm{~ns}$ & $6,46 \mathrm{ab}$ & $15,44 \mathrm{bc} *$ & $1,02 \mathrm{~ns}$ & $31,72 \mathrm{a}$ & $0,65 \mathrm{ab}$ \\
$\mathrm{PLA}$ & 100 & $5,83 \mathrm{~b}$ & $17,34 \mathrm{~b}$ & 0,82 & $27,43 \mathrm{ab}$ & $0,84 \mathrm{ab}$ \\
$\mathrm{HF}$ & 100 & $6,86 \mathrm{a}$ & $21,03 \mathrm{a}$ & 1,52 & $32,90 \mathrm{a}$ & $0,92 \mathrm{a}$ \\
$\mathrm{VB}_{75}+\mathrm{CAC}_{25}$ & 97,92 & $6,35 \mathrm{ab}$ & $15,43 \mathrm{bc}$ & 1,18 & $33,27 \mathrm{a}$ & $0,66 \mathrm{ab}$ \\
$\mathrm{SO}_{75}+\mathrm{VB}_{25}$ & 89,58 & $4,43 \mathrm{c}$ & $13,68 \mathrm{c}$ & 0,94 & $21,56 \mathrm{~b}$ & $0,35 \mathrm{~b}$ \\
\hline $\mathrm{CV}(\%)$ & 8 & 5 & 6 & 24 & 15 & 25 \\
\hline Média & 97,5 & 5,99 & 15,69 & 1,09 & 29,38 & 0,684 \\
\hline
\end{tabular}

* Médias seguidas da mesma letra nas colunas não diferem entre si pelo teste de Tukey $(\mathrm{p}<0,05)$. Tratamentos: VB puro: vermicomposto bovino puro; PLA: Plantmax ${ }^{\oplus}$; HF: Húmus Férti ${ }^{\circledR} ; \mathrm{VB}_{75}+\mathrm{CAC}_{25}$ : vermicomposto bovino $75 \%+$ casca de arroz carbonizada $25 \%$ e $\mathrm{SO}_{75}+\mathrm{VB}$ ${ }_{25}$ : solo $75 \%$ + vermicomposto bovino $25 \%$. ns: não significativo pelo teste de Tukey $(p<0,05)$. CV: coeficiente de variação.

A massa seca de raiz foi significativamente superior quando utilizado o Húmus Fértil ${ }^{\circledR}$; no entanto, o efeito deste não diferiu daquele dos demais substratos, com exceção da combinação de solo $75 \%$ mais vermicomposto bovino $25 \%\left(\mathrm{SO}_{75}+\mathrm{VB}_{25}\right)$, o qual apresentou a menor massa seca de raiz. Este resultado confere com o observado por Smiderle et al. (2001) que verificaram uma redução da massa de matéria seca das raízes das mudas de alface, pepino e pimentão, quando produzidas no substrato Plantmax ${ }^{\circledR}$ mais solo mais areia. Ou seja, de modo geral, substratos formulados com uma dada proporção de solo tendem a apresentar resultados inferiores, quanto aos atributos das mudas que são avaliados. Já em um trabalho conduzido por Trani et al (2007), com o uso dos substratos Plantmax HA (Eucatex), Esfagno (Sarrua) e GIII (Gioplanta), os autores não verificaram diferenças significativas para esta variável.

A formulação de um substrato com combinações de vários materiais permite a obtenção de um produto final com melhores características químicas e físicas, o que possibilita melhores resultados na produção de mudas, conforme pode ser verificado em diversos trabalhos realizados na área da horticultura (Smiderle et al., 2001; Tavares et al., 2006; Silva et al., 2007). Pelo desempenho obtido na produção de mudas de alface, pepino e pimentão, em bandejas de polipropileno expandido, em casa de vegetação, os substratos (Plantmax ${ }^{\oplus}+$ solo e Plantmax ${ }^{\circledR}+$ areia) são recomendados por Smiderle et al. (2001). Ainda, é conveniente destacar que a forma de propagação utilizada no cultivo do meloeiro consiste, praticamente, no uso de recipientes multicelulares: as bandejas de polipropileno ou de plástico. Já a propagação em canteiros no solo (sementeira de chão), não é recomendável para o cultivo do meloeiro, pois o sistema radicular praticamente não suportaria o transplantio de mudas de raízes nuas, em função da baixa capacidade de recuperação de danos bem como, por questões fitossanitárias (Dias \& Costa, 2010).
Em função dos resultados obtidos, verifica-se que os substratos orgânicos são bons materiais suporte para a produção de mudas. A combinação de vermicomposto bovino $75 \%$ mais casca de pinus $25 \%$ mostrouse o substrato mais eficiente para produção de mudas de alface em sistema "Floating" em ambiente protegido (Tavares et al., 2006). Tiago et al. (2008) verificaram sensível aumento na comunidade de bactérias, fungos e micro-organismos totais (bactérias + fungos), em substratos adubados com vermicompostos de bovino e equino, quando o bovino aumentou as UFC em $93,7 \%$. Esse aumento da população de micro-organismos totais (bactérias e fungos) é favorável às plantas, pois, por seus efeitos diretos ou indiretos, eles controlam a transformação, a ciclagem e a disponibilidade de nutrientes para o solo e a planta (Siqueira \& Moreira, 2002). Já a casca de arroz carbonizada confere qualidades físicas importantes ao processo de produção de mudas, como umidade, porosidade e drenagem adequadas (Zietemann \& Roberto, 2007), cuja condição merece atenção, principalmente quando utilizado sistema de irrigação por nebulização intermitente, situação em que a casca de arroz carbonizada proporciona pouca drenagem (Hoffmann et al., 2005). Aliado a estes materiais, o substrato comercial Plantmax ${ }^{\circledR}$ tem como vantagem a uniformidade da composição química e física, assim como o Húmus Fértil ${ }^{\circledR}$. Essa característica apresenta-se como fundamental para a produção comercial de mudas e, de forma especial, para a pesquisa, haja vista a segurança na repetibilidade dos resultados (Hoffmann et al., 2005). No entanto, possivelmente, pelo fato de o solo apresentar maior densidade que os demais substratos testados, quando incluso na composição com o vermicomposto bovino, sendo este utilizado em menores proporções (25\%), sua eficiência quanto às respostas a este experimento, foram inferiores. 


\section{CONCLUSÕES}

Para a produção de mudas de meloeiro amarelo sob cultivo protegido, é possível utilizar substratos isoladamente ou efetuar uma composição de substratos.

De acordo com os resultados obtidos, dentre os substratos utilizados deve-se evitar o uso de solo $75 \%$ em combinação com vermicomposto bovino $25 \%$, na produção de mudas de meloeiro amarelo 'Gold Mine'.

\section{REFERÊNCIAS}

Bezerra FC (2003) Produção de mudas de hortaliças em ambiente protegido. Fortaleza, Embrapa Agroindústria Tropical. 22p. (Embrapa Agroindústria Tropical. Documentos, 72).

Carvalho NM \& Nakagawa J (2000) Sementes: ciência, tecnologia e produção. Jaboticabal, FUNEP. 588p.

Dias R de CS \& Costa ND (2010) Sistemas de Produção de Melão. Propagação. Petrolina, Embrapa Semiárido (Sistemas de Produção, 5). Disponível em: < http://sistemasdeproducao.cnptia.embrapa.br/FontesHTML/Melao/SistemaProducaoMelao/producao_de_mudas.html > Acessado em: 6 de junho de 2012.

Hoffmann A, Pasqual M, Chalfun NNJ \& Fráguas CB (2001) Efeito de substratos na aclimatização de plantas micropropagadas de porta-enxertos de macieira "Marubakaido". Ciência e Agrotecnologia, 25:462-467.

Hoffmann A, Fachinello JC \& Nachtigal JC (2005) Formas de propagação de plantas frutíferas. In: Fachinello JC, Hoffmann A \& Nachtigal JC (Eds.) Propagação de Plantas Frutíferas. Brasília, Embrapa Informação Tecnológica. p.45-56.

Kämpf AN (2005) Substrato. In: Kämpf NA (Ed.) Produção comercial de plantas ornamentais. Guaíba, Agropecuária. p.45-72.

Labouriau LG \& Valadares MEB (1976) On the germination of seeds Calotropis procera (Ait.) Ait.f. Anais da Academia Brasileira de Ciências, 48:263-284.

Lima JF, Silva MPL, Teles S, Silva F \& Martins GN (2010) Avaliação de diferentes substratos na qualidade fisiológica de sementes de melão de caroá [Sicana odorifera (Vell.) Naudim]. Revista Brasileira de Plantas Medicinais, 12:163-167.

Machado AA \& Conceição AR (2003) Sistema de análise estatística para Windows. Winstat. Versão 2.0, UFPel. CD-ROM.

Marcos Filho J (2005) Fisiologia de sementes de plantas cultivadas. Piracicaba, FEALQ. 495p.

Martins CC, Nakagawa J \& Bovi MLA (1999) Efeito da posição da semente no substrato e no crescimento inicial das plântulas de palmito-vermelho (Euterpe espiritosantensis). Revista Brasileira de Sementes, 21:164-173.

Serviço Nacional de Aprendizagem Rural (SENAR) (2007) Cultivo de melão: manejo, colheita, pós-colheita e comercialização. Brasília, SENAR. 104p.

Silva EA da, Maruyama WI, Mendonça V, Bardiviesso DM, Nunes GH de S \& Biscaro GA (2007) Diferentes substratos na emergência de sementes e na produção de mudas de melão amarelo. In: $47^{\circ}$ Congresso Brasileiro de Olericultura, Porto Seguro. Disponível em: <http://www.abhorticultura.com.br/eventosx/ ViewTrabalho.aspx ?idtrabalho $=525 \&$ idevento $=1 \&$ tipo $=$ TRABALHOS $>$. Acessado em: 6 de junho de 2010 .

Siqueira JO \& Moreira FMS (2002) Biologia e bioquímica do solo Lavras, Lavras, UFLA/FAEPE. 626p.
Smiderle OJ, Salibe AB, Hayashi AH \& Minami K (2001) Produção de mudas de alface, pepino e pimentão em substratos combinando areia, solo e Plantmax ${ }^{\circledR}$. Horticultura Brasileira, 19:353357.

Tavares LC, Lemos FD, Finatto JA, Oliveira Filho LCI de \& Morselli TBGA (2006) Produção de mudas de alface (lactuca sativa 1 . cv. mimosa) em substratos alternativos. In: $15^{\circ}$ Congresso de Iniciação Científica, Pelotas, UFPel. Disponível em: <http://www.ufpel.edu.br/cic/2006/arquivos/CA_01381.rtf> Acessado em: 5 de junho de 2010.

Tiago RV, Melz EM \& Schiedeck G (2008) Comunidade de bactérias e fungos de estercos antes e após vermicompostagem e no substrato hortícola após uso de vermicomposto. Revista Ciência Agronômica, 39:187-192.

Trani PE, Feltrin DM, Pott CA \& Schwingel M (2007) Avaliação de substratos para produção de mudas de alface. Horticultura Brasileira. 25:256-260.

Zietemann C \& Roberto SR (2007) Produção de mudas de goiabeira (Psidium guajava L.) em diferentes substratos. Revista Brasileira de Fruticultura, 29:137-142. 